\title{
To study of Life Time Prediction of Nylon Rope using Aging Property, Thermal Behavior and Physical Properties'
}

\author{
Ms.Pragati gajbhiye, Mr.Praveen kumar singh \\ Barkatullah university institute of Technology, bhopal
}

\begin{abstract}
This work aim is To study of Life Time Prediction of Nylon Rope using Aging Property, Thermal Behavior and Physical Properties In This work taking nylon rope experimental test were performed in ASTM D3045 standard for breaking strength. firstly in this project the nylon rope samples are keep in heat aging oven at $70^{\circ} \mathrm{c}$ temperature for $0,1,3,6,12,23$ weeks. after the completion, test the material in universal testing machine for breaking strength

In the present investigation the Breaking Strength, was determined as a function of time with the constant exposure to the plastic product at $70^{\circ} \mathrm{C}$ for 23 week. The sample was initially determined the properties and considered as 0 days sample or base property of the material. The sample was drawn in the interval of $B$ 1,3,6,12,23 Weeks.

The regression analysis was conducted on the test data and the prediction of the life span of the products was made as per ASTM. Use the regression equation to determine the exposure time necessary to produce a predetermined level of property change. An acceptable regression equation must have an $r^{2}$ of at least 80
\end{abstract}

\section{Introduction}

Nylon is a generic designation for a family of synthetic polymers known generically as aliphatic polyamides first produced on February 28, 1935, by Wallace Carothers at DuPont's research facility at the DuPont Experimental Station. Nylon is one of the most commonly used polymers. Key representatives are nylon-6,6; nylon-6; nylon-6,9; nylon-6,10; nylon-6,12; nylon-11; nylon-12 and nylon-4,6

Nylon was intended to be a synthetic replacement for silk and substituted for it in many different products after silk became scarce during World War II. It replaced silk in military applications such as parachutes and flak vests, and was used in many types of vehicle tires. Nylon fibres are used In many applications, including clothes fabrics, bridal veils, package paper, carpets, musical strings, pipes, and rope. Solid nylon is used in hair combs

\section{Nylon Rope}

Nylon is the strongest of all ropes in common use. It is used for absorbing shock loads, such as when lifting or towing because it has the ability to return to it's original length after being stretched. It also has good abrasion resistance and can last several times longer than natural fibres. It is also resistant to oil and most chemicals. Like manila, nylon has good resistance to ultraviolet deterioration from sunlight. Nylon is ideal for use as bow-to-s climbing ropes, safety lines, lariat ropes, boat falls, drop hammer ropes, target tow rope, fishing ropes and industrial slings. and it is specific gravity is 1.14

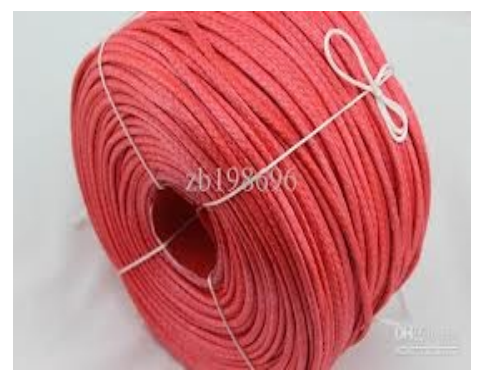

\section{Concepts of nylon production:-}

The first approach: combining molecules with an acid $(\mathrm{COOH})$ group on each end are reacted with two chemicals that contain amine $\left(\mathrm{NH}_{2}\right)$ groups on each end. This process creates nylon 6,6 , made of hexamethylene diamine with six carbon atoms and adipic acid

The second approach: a compound has an acid at one end and an amine at the other and is polymerized to form a chain with repeating units of $\left(-\mathrm{NH}-\left[\mathrm{CH}_{2}\right]_{\mathrm{n}}-\mathrm{CO}-\right)_{\mathrm{x}}$. In other words, nylon 6 is made from a single six- 
carbon substance called caprolactam. In this equation, if $\mathrm{n}=5$, then nylon 6 is the assigned name (may also be referred to as polymer).

\section{Test Methodology}

The failure criterion may be defined as an unacceptable change in the function which causes a particular failure. Changes may be in stress relaxation, stiffness/modulus, creep, tear resistance, swelling, dielectric properties, etc. The underlying mechanism involved in this change must be determined by an accelerated laboratory test at different levels of severity and at different time intervals. It is important to keep the accelerated test condition similar to the service condition and perform the test at multiple temperatures higher than the average service temperature

\section{Heat Aging, Oven Aging ;-}

Oven aging is often used to accelerate the aging process. It is also a way of imitating conditions the specimen may be exposed to in the product lifetime. Standard testing can be performed on the aged samples and comparison can be made to non-aged samples

Test The samples are placed in an aging oven. The temperature and the duration is specified by the customer. The specimens are removed and tested after oven aging is complete.

Size; Sample size is dependent on the tests to be performed after the aging process

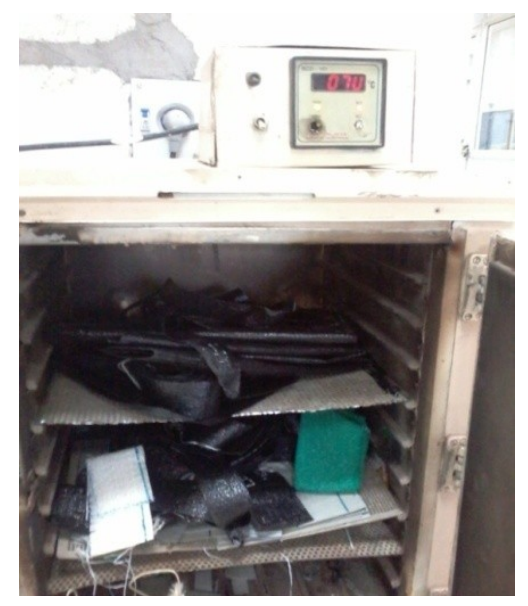

Stage-I: Preparation of specimens according to the time and temperature to be exposed.

Stage-II: Exposure of samples at different temperature

Stage-III: Properties evaluation at different temperature levels

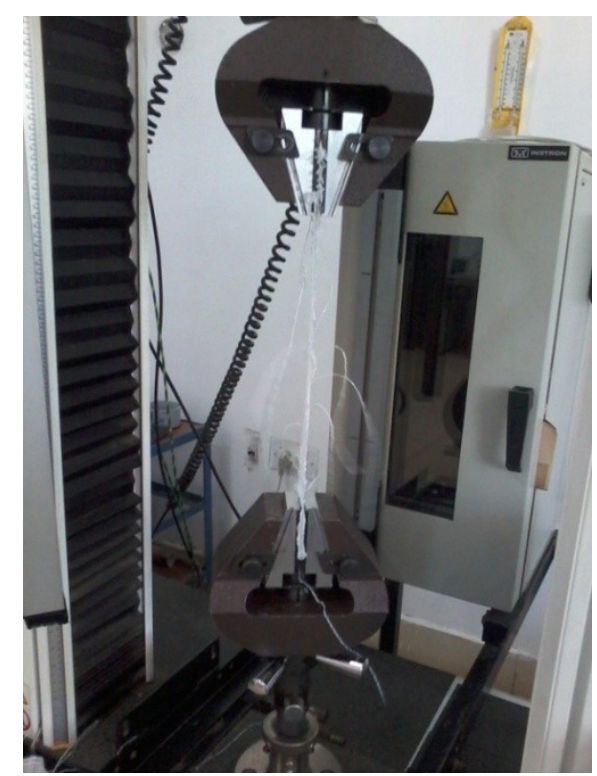


Breaking Strength :

Test condition; $-70^{\circ} \mathrm{c}$ (Hot Air Oven)

Outer diameter;-3.10mm

Rate; $-500 \mathrm{~mm} / \mathrm{min}$

Test started date;-20-jan-2014

Test completed Date;-30-jun-2014

Stage-IV: Regression analysis of the plastic products which is tested.

Stage-V Preparation of final report

The following Properties were measured in the interval time duration of 0 to 23 weeks. The test values obtained as follows.

Test -I for 0 week

\begin{tabular}{|c|c|c|c|c|c|}
\hline Week & Sample-1 & Sample-2 & Sample-3 & Sample-4 & Sample-5 \\
\hline 0 & 2833 & 2827 & 2835 & 2830 & 2825 \\
\hline average & 2830 & & & & \\
\hline
\end{tabular}

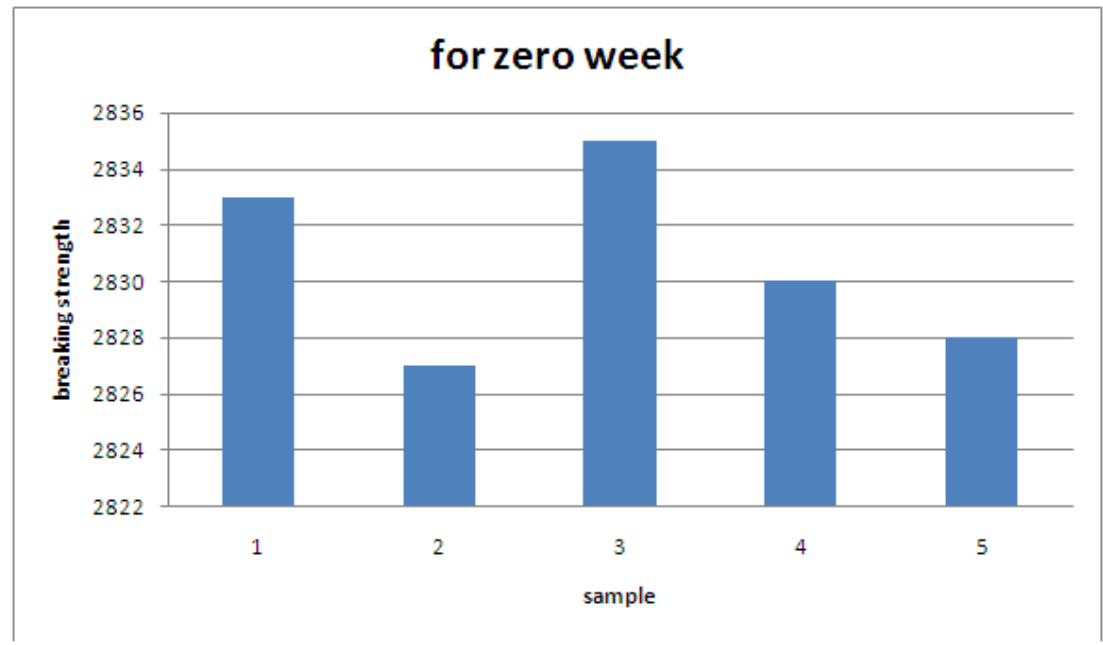

Test -II for 1 week

\begin{tabular}{|c|c|c|c|c|c|}
\hline Week & Sample-1 & Sample-2 & Sample-3 & Sample-4 & Sample-5 \\
\hline 1 & 2826 & 2830 & 2835 & 2833 & 2820 \\
\hline average & 2828 & & & & \\
\hline
\end{tabular}

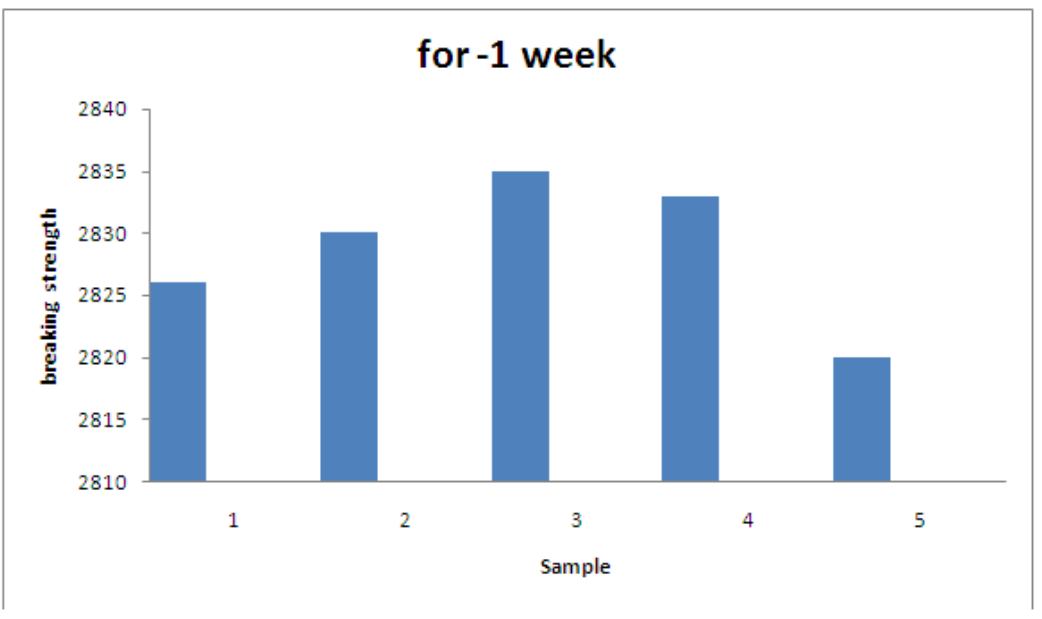

Test -III for 3 week

\begin{tabular}{|c|c|c|c|c|c|}
\hline Week & Sample-1 & Sample-2 & Sample-3 & Sample-4 & Sample-5 \\
\hline 3 & 2810 & 2820 & 2825 & 2831 & 2826 \\
\hline average & 2820 & & & & \\
\hline
\end{tabular}




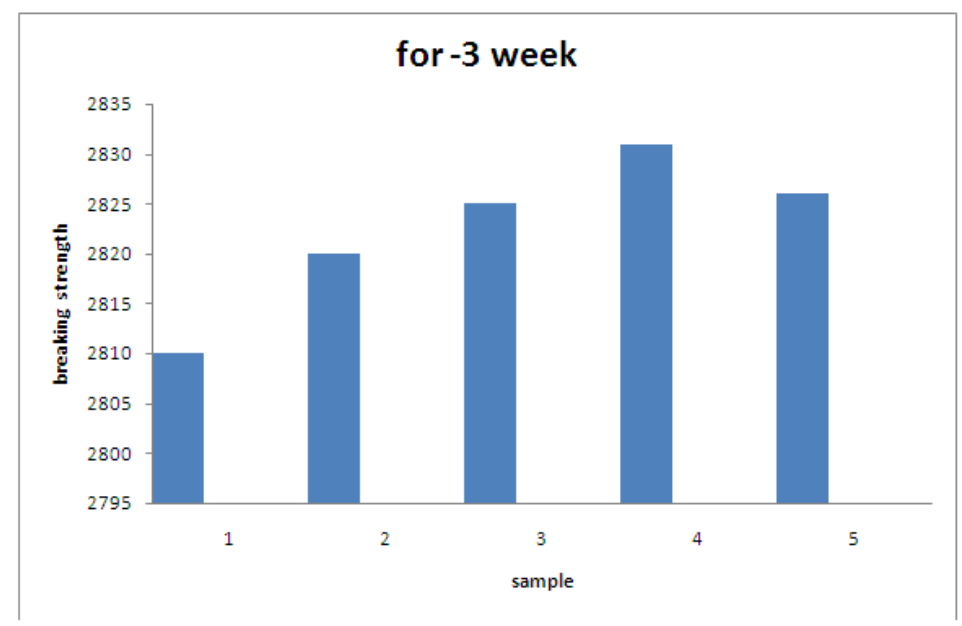

Test -IV for 6 week

\begin{tabular}{|c|c|c|c|c|c|}
\hline Week & Sample-1 & Sample-2 & Sample-3 & Sample-4 & Sample-5 \\
\hline 6 & 2813 & 2817 & 2819 & 2820 & 2821 \\
\hline average & 2818 & & & & \\
\hline
\end{tabular}

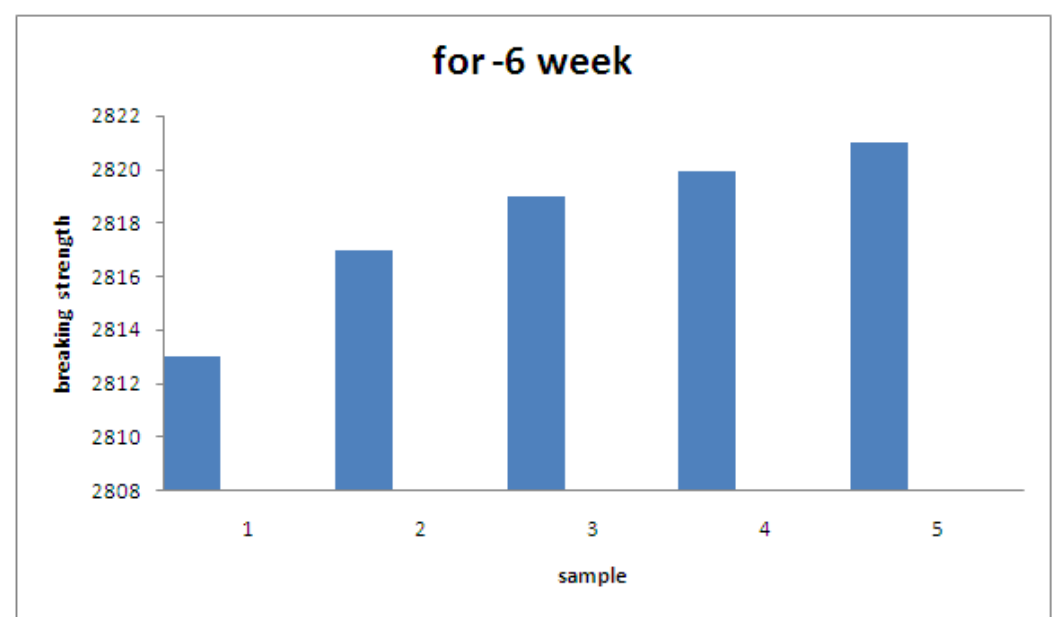

Test $-\mathrm{V}$ for 12 week

\begin{tabular}{|c|c|c|c|c|c|}
\hline Weeks & Sample-1 & Sample-2 & Sample-3 & Sample-4 & Sample-5 \\
\hline 12 & 2802 & 2805 & 2810 & 2801 & 2802 \\
\hline average & 2804 & & & & \\
\hline
\end{tabular}

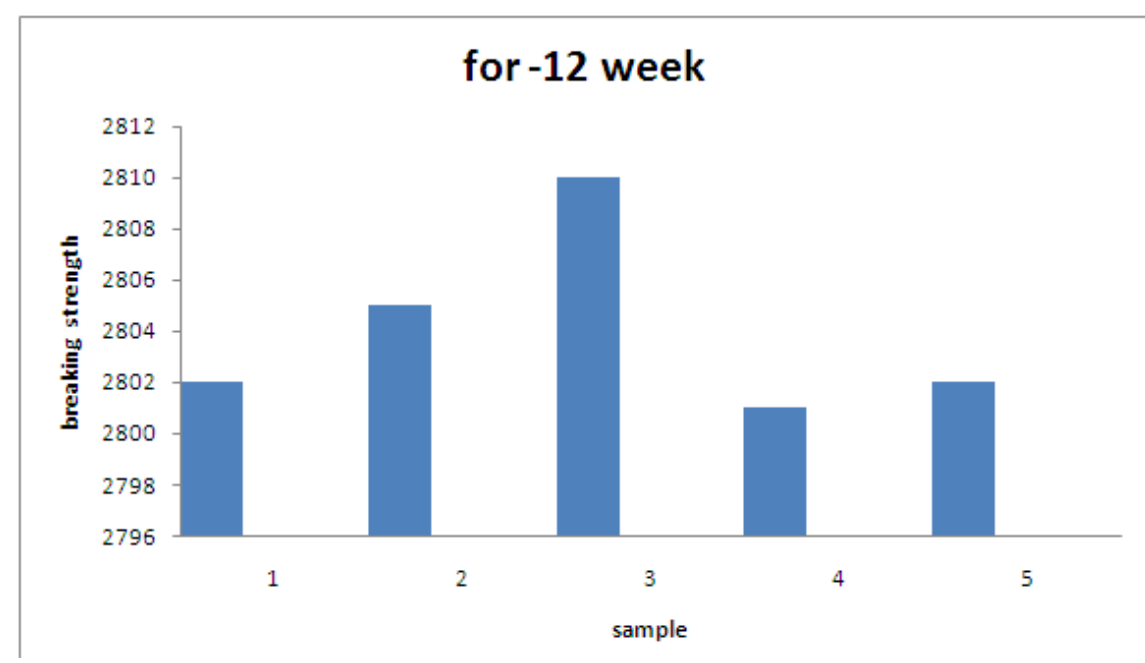


Test -IV for 23 week

\begin{tabular}{|c|c|c|c|c|c|}
\hline Weeks & Sample-1 & Sample-2 & Sample-3 & Sample-4 & Sample-5 \\
\hline 23 & 2798 & 2788 & 2780 & 2795 & 2793 \\
\hline Average & $\mathbf{2 7 9 0}$ & & & & \\
\hline
\end{tabular}

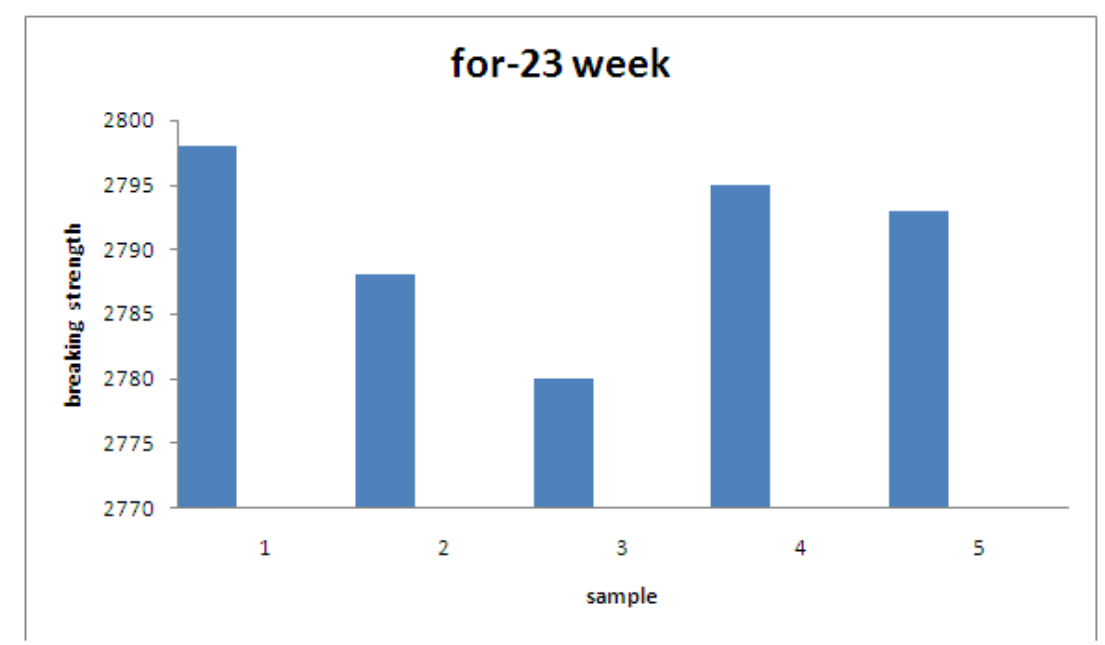

Breaking strength Vs ExposureTime

\begin{tabular}{|c|c|}
\hline \multicolumn{2}{|c|}{ Breaking strength Vs ExposureTime } \\
\hline Exposure Time(week) & Avg.Breaking Strength(N) \\
\hline 0 & 2830 \\
\hline 1 & 2828 \\
\hline 3 & 2820 \\
\hline 6 & 2818 \\
\hline 12 & 2804 \\
\hline 23 & $\mathbf{2 7 9 0}$ \\
\hline
\end{tabular}

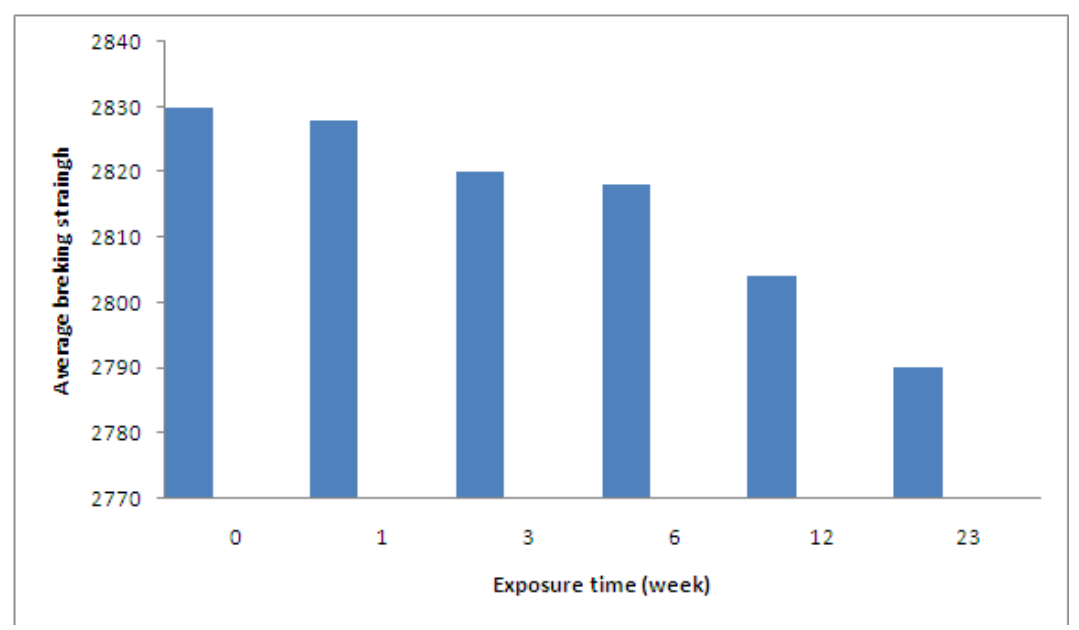

Regression Analysis of Breaking strength

Prediction of time period for $80 \%$ deterioration Breaking Strength to the Average Breaking strength values calculated for 23 weeks

\begin{tabular}{|c|c|c|c|c|c|c|c|}
\hline Sl No & $\mathrm{Xi}$ & $\mathrm{Yi}$ & $x i-x$ & yi-y & $(x i-x)^{2}$ & $(y i-y) 2$ & $(x-x i)(y-y i)$ \\
\hline 1 & 0 & 2830 & -7.5 & 15 & 56.25 & 225 & -112.5 \\
\hline 2 & 1 & 2828 & -6.5 & 13 & 42.25 & 169 & -84.5 \\
\hline 3 & 3 & 2820 & -4.5 & 5 & 20.25 & 25 & -22.5 \\
\hline 4 & 6 & 2818 & -1.5 & 3 & 2.25 & 9 & -4.5 \\
\hline 5 & 12 & 2804 & 4.5 & -11 & 20.25 & 144 & -49.5 \\
\hline 6 & 23 & 2790 & 15.5 & -25 & 240.25 & 625 & -387.5 \\
\hline sum & 45 & 16890 & 0 & 0 & 381.5 & 1197 & -661 \\
\hline Avg & 7.5 & 2815 & & & & & \\
\hline $\mathrm{Y}=$ & \multicolumn{7}{|c|}{$\mathrm{b} 0+\mathrm{b} 1 \mathrm{X}$} \\
\hline
\end{tabular}


To study of Life Time Prediction of Nylon Rope using Aging Property, Thermal Behavior .....

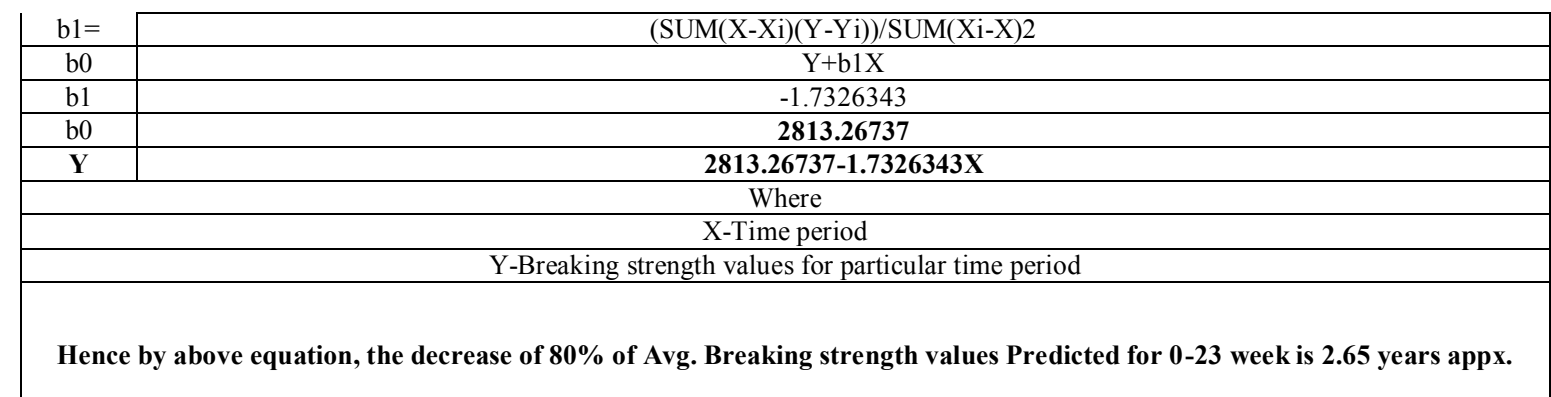

\section{Results And Discussion}

In the present investigation the Mass, Breaking Strength, was determined as a function of time with the constant exposure to the plastic product at $70^{\circ} \mathrm{C}$ for 23 week. The sample was initially determined the above properties and considered as 0 days sample or base property of the material. The sample was drawn in the interval of B-1,3,6,12,23 Weeks.

The regression analysis was conducted on the above test data and the prediction of the life span of the products was made as per ASTM. Use the regression equation to determine the exposure time necessary to produce a predetermined level of property change. An acceptable regression equation must have an $r^{2}$ of at least $80 \%$.

[1]. en.wikipedia.org/wiki/Nylon

\section{Referenced Documents}

[2]. www.indiasafetynet.co.in/Nylon-Ropes

[3]. www.engineeringtoolbox.com/nylon-rope-strength-d 1513.html

[4]. www.ropesandtwines.com/nylonrope.asp

\section{Astm Standards}

- ASTM D 3045 Test Method Standard Practice for Heat Aging of Plastics Without Load

- ASTM D 573 Test Method for Rubber-Deterioration in an Air Oven.

- ASTM D 618 Practice for Conditioning Plastics for Testing.

- ASTM D 883 Terminology Relating to Plastics.

- ASTM D 1870 Practice for Elevated Temperature Aging Using a Tubular Oven3.

- ASTM D 1898 Practice for Sampling of Plastics3.

- ASTM E 145 Specifications for Gravity-Convection and Forced-Ventilation Ovens.

- ASTM E 456 Terminology Relating to Quality and Statistics.

\section{Iso Standard:}

- ISO 2578 (1974) Determination of Time-Temperature Limits After Exposure to Prolonged Action of Heat.

\section{References Indian Standard}

- IS 1964 (2001): Methods for Determination of Mass per Unit Lenght and Mass per Unit Area of Fabrics [TXD 1: Physical Methods of Tests]. 